\title{
AS VIOLAÇÕES SOFRIDAS PELO POVO KRENAK E O DANO CAUSADO AO PROJETO DE VIDA
}

\author{
Paulo Gilberto Cogo Leivas ${ }^{1}$ \\ Rodrigo de Medeiros Silva ${ }^{2}$
}

\begin{abstract}
Resumo
Este artigo versa sobre as violações cometidas pelo Regime Militar ao povo Krenak e o possível dano ao projeto de vida. Conceituando esta espécie de dano como violação de direitos humanos, irá discorrer sobre a criação da Guarda Rural Indígena (GRIN), a instalação do presídio indígena em suas terras chamado "Reformatório Krenak" e o deslocamento forçado para outro centro de detenção indígena, denominado fazenda Guarani, no município de Carmésia/MG. Procurará se demonstrar que as ações cometidas a este povo, pelo Estado Brasileiro, devem ser reparadas também por atingir o modo e a expectativa de vida que possuíam a época. Para melhor identificar estes danos causados, o trabalho recorrerá à peça inicial da Ação Civil Pública no 64483-95.2015.4.01.3800, impetrada pelo Ministério Público Federal, que trata das violações sofridas pelos Krenak e o Relatório da Comissão Nacional da Verdade, Volume II. Também se demostrará que a Corte Interamericana de Direitos Humanos já vem entendendo que este tipo de dano deve ser reparado.
\end{abstract}

Palavras-chave: Direitos humanos. Ditadura militar. Comissão Nacional da Verdade. Povo Krenak. Dano ao projeto de vida.

\section{THE VIOLATIONS SUFFERED BY THE KRENAK PEOPLE AND THE DAMAGE CAUSED TO THE PROJECT OF LIFE}

\section{Abstract:}

This article deals with the violations committed by the Military Regime to the Krenak people and the possible damage to the life project. Conceiving this kind of damage as a violation of human rights, he will address the creation of the Indigenous Rural Guard (GRIN), the installation of the indigenous prison on their lands called the "Krenak Reformatory" and the forced displacement to another indigenous detention center called the farm Guarani, in the municipality of Carmésia / MG. It will try to demonstrate that the actions committed to this people, by the Brazilian State, must also be repaired for achieving the way and the life expectancy that had the time. In order to better identify these damages, the work will refer to the initial piece of Public Civil Action No. 64483-95.2015.4.01.3800, filed by the Federal Public Ministry, which deals with the violations suffered by the Krenak and the Report of the National Commission of Truth, Volume II . It will also be demonstrated that the InterAmerican Court of Human Rights has already understood that this type of damage must be repaired.

\footnotetext{
${ }^{1}$ É graduado em Ciências Jurídicas e Sociais pela Universidade Federal do Rio Grande do Sul (1993), Mestre em Direito pela Universidade Federal do Rio Grande do Sul (2002) e Doutor em Direito pela Universidade Federal do Rio Grande do Sul (2009). É Professor do Curso de Mestrado em Direitos Humanos da UNIRITTER/Porto Alegre, onde leciona a disciplina de Teoria dos Direitos HUmanos. É Professor de Ética e Direito da Universidade Federal de Ciências da Saúde de Porto Alegre (UFCSPA), onde leciona disciplina de Direitos Humanos e Saúde, Bioética e Direito Sanitário.

${ }^{2}$ Graduado em Direito pela Universidade de Fortaleza-UNIFOR, Fortaleza-CE (2003), possui especialização em Direito Civil e Processual Civil, pelo Instituto de Desenvolvimento Cultural - IDC, em Porto Alegre-RS (2016), é Mestrando em Direito (área de concentração em Direitos Humanos), na UniRitter, em Porto Alegre-RS (2017/2018).
} 
Keywords: Human rights. Military dictatorship. National Truth Commission. Krenak people. Damage to the life project.

\section{INTRODUÇÃ̃}

O dano ao projeto de vida, por vezes, também chamado no Brasil de dano existencial, é uma espécie de dano imaterial causado ao modo de vida e a expectativa que o sujeito atingido tinha sobre ela até ser afetado, alterando relações familiares, sociais, culturais, etc (SOARES, 2009, p.44). Tratado aqui como uma espécie de dano imaterial, pode ser um instituto utilizado na esfera cível, de família, em questões ambientais ou trabalhistas (SOARES, 2009, 65-77). Assim, a doutrina já aceita e bem conceitua este dano(LUTZKY, 2012, p.142), visando não só tolher que outras violações sejam cometidas, mas também a justiça social.

A reparação de dano imaterial encontra fundamento na Constituição Federal (art. $5^{\circ}$, incisos V e X e art. 114, inciso VI, da CF/88), como no Código Civil Brasileiro (arts. 186 e 927). O dano ao projeto de vida já possui precedentes na Corte Interamericana de Direitos Humanos. Discutir-se-á, a partir da petição inicial da Ação Civil Pública $n^{0}$ 6448395.2015.4.01.3800, impetrada pelo Ministério Público Federal- MPF $^{3}$, se o povo Krenak sofreu também dano ao projeto de vida, e que alguns dos pedidos formulados na Ação vão ao encontro desta justa reparação.

O povo Krenak, originalmente, espalhado por onde hoje são os Estados da Bahia, Espírito Santo e Minas Gerais, sofreu perseguição estatal, desde a época da colonização portuguesa. Este tratamento se intensificou no início do século XIX, tendo como fechamento deste histórico de violações, os atos cometidos pela Ditadura Militar, quais sejam, a criação da Guarda Rural Indígena (GRIN), a instalação do presídio indígena em suas terras chamado "Reformatório Krenak" e o deslocamento forçado para outro centro de detenção indígena, denominado fazenda Guarani, no município de Carmésia/MG. Este artigo se deterá nas violações cometidas pela Ditadura, no intuito de debater a necessidade da reparação também ao projeto de vida atingido. Os Krenak, outrora chamados de botocudos, ainda sofrem reflexos das ações acima citadas e possuem o direito desta reparação.

O MPF em sua ação pede a condenação, dentre outros pontos, a reparar danos morais coletivos sofridos pelo Povo Krenak. Apesar da Constituição brasileira trazer o termo danos morais, a doutrina e jurisprudência vêm preferindo os termos dano imaterial ou extrapatrimonial, do qual o dano moral e o dano ao projeto de vida seriam espécies. Asssim, traz-se a discussão se, além da indenização por danos morais coletivos ao Fundo de Direitos Difusos, não se deveria ter também condenação pecuniária referente ao dano ao projeto de vida. Sem prejuízo desta discussão, o MPF formula outros pedidos que procuram reparar ou mitigar o dano ao projeto de vida, que serão vistos no decorrer do trabalho.

A Comissão Nacional da Verdade, também, no Volume II de seu relatório, traz provas e relatos sobre as violações sofridas pelos Krenak. Inclusive, tal documento é utilizado pelo MPF. Se verá no decorrer do trabalho que a Corte Interamericana de Direitos Humanos já condena à reparação por danos ao projeto de vida. O Estado brasileiro teria agido de forma a causar este tipo de dano, devendo, então, como busca o MPF, em sua ação judicial reparar o povo indígena em questão.

\footnotetext{
${ }^{3}$ Ação Civil Pública no 0064483-95.2015.4.01.3800. Autor: Ministério Público Federal; Reús: União Federal, Estado de Minas Gerais, Fundação Rural Mineira, Fundação Nacional do Índio e Manoel dos Santos Pinheiro. Assunto da petição: Direitos Indígenas. 14ª Vara da Justiça Federal de Minas Gerais.
} 
A importância de se espeficar o dano ao projeto de vida se dá para que possa ser também reparado com justeza e não englobado por outro dano do mesmo gênero. Após décadas de danos sofridos, como no caso dos Krenak, e a força do impacto destes, o mais correto seria falar em mitigação do que reparação. Todavia, nem por isso deve se deixar de buscar a justiça social, por meio do Poder Judiciário, que não pode se eximir de apreciar toda lesão ou ameaça de direito (art. $5^{\circ}, \mathrm{XXXV}$, da CF).

A lista de violações sofridas pelos Krenak é extensa, podendo ser verificada pelos direitos dispostos na Constituição Federal de 1988, legislação infra e dispositivos internacionais, como a Convenção 169 da OIT, Declaração das Nações Unidas para os Povos Indígenas, Convenção Americana sobre Direitos Humanos, dentre outros. A relevância desta reparação se dá não só pelos Krenak, como para outras tantas dezenas ou centenas de povos indígenas que sofreram e sofrem por ações violadoras do Estado brasileiro. Percebe-se, como fundamento discursivo para tais violações, de forma reiterada, um "desenvolvimento" econômico do país, que nega a pluralidade de povos e culturas que o contitui. Tal fundamentação também não seria admitida pelo ordenamento jurídico, afinal a ordem econômica deve observar os ditames da justiça social, conforme diversos princípios (art. 170, da CF).

O presente trabalho, assim, busca, por meio da caracterização do dano ao projeto de vida sofrido pelos Krenak durante a ditadura militar, demonstrar que este deve ser reparado, para se realizar direitos humanos. A identificação e condenação, por parte do Poder Judiciário, destes danos sofridos pelas populações indígenas durante o supramencionado Regime termina por realizar fundamento da República brasileira (art. $1^{\circ}$, III, da CF), como alguns de seus objetivos como construir uma sociedade livre, justa e solidária e reduzir as desigualdades sociais (art. $3^{\circ}$, I e III, da CF). Sem prejuízo destes valores positivados, em respeito a estas populações e suas culturas, procurar de forma mais efetiva protegê-las e repará-las, quando violadas.

\section{DO DANO AO PROJETO DE VIDA}

O dano ao projeto de vida ainda é pouco desenvolvido na doutrina brasileira (ALMEIDA, SCHÄFER, 2017, p. 6). Não se confundiria com o dano existencial, apesar de boa parte da doutrina e jurisprudência brasileira assim tratar do assunto. Ou, quando muito, colocar o dano ao projeto de vida como uma subespécie daquele:

\footnotetext{
A doutrina brasileira normalmente aborda o dano existencial e o dano ao projeto de vida conjuntamente. No entanto, importante esclarecer que dano existencial e dano ao projeto de vida não são sinônimos [...]Demonstra-se que há diferenças conceituais entre o dano existencial e o dano ao projeto de vida [...]A doutrina brasileira conceitua o dano ao projeto de vida colocando-o como uma subespécie do dano existencial (ALMEIDA E SCHÄFER, 2017, p.7).
}

A crítica dos autores acima ao que seria uma imprecisão ou confusão feita no Brasil deve ser levado em consideração, mas este artigo não se aterá a este debate. Mas para além desta discussão, os autores também afirmam que a doutrina brasileira aceita o dano ao projeto de vida chamando-o de dano existencial:

Os doutrinadores brasileiros utilizam em sua maioria do conceito de dano ao projeto de vida e somente o denomina de dano existencial, mas não se utiliza do conceito desenvolvido na Europa. Portanto, podemos entender que a doutrina brasileira aceita o dano ao projeto de vida. A categorização adequada de 
danos nos permite, em primeiro lugar, uma reparação integral, justa, e, em segundo lugar, a correta classificação permite evitar a banalização do dano moral e a ampliação de masiada das espécies de dano $(2017$, p. 10).

Destaca-se que ainda que a Corte Interamericana de Direitos Humanos, de acordo com Almeida e Schäfer (2017, p.1) utiliza a sua compreensão de dano ao projeto de vida, na qual encontra fundamento doutrinário em Carlos Fernández Sessarego (2015). Todavia, como dito acima, este trabalho não abordará estas diferenças, apesar de respeitá-las, tratando de dano tendo em conta o seguinte conceito:

\begin{abstract}
O projeto de vida é a liberdade, que desponta de uma decisão, uma escolha de um projeto específico, avaliando/estimando diante das oportunidades apresentadas, de acordo com os seus valores (o que se mostra valioso para realizar), experiências e vocações pessoais, em um determinado período histórico visando o futuro, dando um sentido à nossa existência e é desta maneira que a vida humana se comporta. Assim, tentamos de todas as maneiras executá-lo, tecendo o nosso destino, salvo se houver alguma mudança no projeto existencial (Almeida e Schäfer, 2017, p.3)
\end{abstract}

A Corte Interamericana de Direitos Humanos-CIDH vem reconhecendo o dano ao projeto de vida em alguns casos, como Cabrera Garcia Vs. México ${ }^{4}$ e Loyaza Tamayo Vs. Peru ${ }^{5}$. A importância disto é destacado no voto de Cançado Trindade e Alirio Abreu Burelli (2017), no último caso citado:

Você precisa reorientar e enriquecer a jurisprudência internacional sobre reparações com foco e própria contribuição do direito internacional dos direitos humanos. Daí a importância que atribuímos ao reconhecimento neste acórdão do Tribunal, o dano ao projeto de vida da vítima, como um primeiro passo nessa direção e propósito. Se houvesse uma determinação de ocorrência de dano ao projeto de vida, como restitutio in integrum seria alcançado como uma forma de reparação? Como proceder com a recuperação da vítima como uma forma de reparação? Como convincente afirmar a garantia de não repetição dos atos ilícitos sob reparos? (tradução livre)

Assim, partindo deste entendimento, que o dano existencial ou ao projeto de vida é plenamente aceito no Brasil e na $\mathrm{CIDH}$, que este trabalho se desenvolverá. Pressuposto necessário para discussão de aplicabilidade ou não de instituto no caso em concreto que será ainda apresentado.

\title{
2.1. O dano ao projeto de vida
}

O dano ao projeto de vida, por vezes, também chamado pela doutrina e jurisprudência brasileiras de dano existencial, é o dano acarretado à maneira que a pessoa vive e a expectativa que possui de desenvolver a sua existência, alterando suas relações em diversas ordens, sejam familiares, sociais, culturais etc. (SOARES, 2009, 44). Está classificado com uma espécie de dano imaterial, no qual outras espécies seriam, por exemplo, o dano estético, o dano autoral, o dano moral, etc. Os danos material e imaterial encontram fundamento constitucional, no art. $5^{\circ}, \mathrm{V}$ e X. Além disto, o $\$ 2^{\circ}$, do mesmo dispositvo, assegura também proteção a outros direitos e garantias trazidos por tratados internacionais. O Código Civil Brasileiro também assegura esta reparação nos arts. 186 e 927.

Todo o ordenamento jurídico brasileiro e internacional visa esta proteção e resguardo, identificado neste dever de reparar:

\footnotetext{
${ }^{4}$ http://www.corteidh.or.cr/CF/jurisprudencia2/ficha_tecnica.cfm?nId_Ficha=343

${ }^{5} \mathrm{http}: / /$ www.corteidh.or.cr/cf/jurisprudencia2/ficha_tecnica.cfm?nId_Ficha=311\&lang=es
} 
Os princípios do neminem laedere (não lesar ninguém) e do alterum non laedere (não lesar outrem), dão a exata dimensão do sentido de responsabilidade. A ninguém se permite lesar outra pessoa sem a consequência de imposição da sanção. No âmbito penal a sanção atende a um anseio da sociedade e busca resguardá-la. No âmbito civil o dever de reparar assegura que o lesado tenha o seu patrimôniomaterial e moral- reconstituído ao status quo ante, mediante a restitutiu in integrum (STOCO, 2007, p.114).

O dano ao projeto de vida ou existencial seria um fato jurídico, assim, bem definido pela doutrina:

O dano existencial é a lesão ao complexo de relações que auxiliam no desenvolvimento normal da personalidade do sujeito, abrangendo a ordem pessoal ou a ordem social. É uma afetação negativa, total ou parcial, permanente ou temporária, seja a uma atividade, seja a um conjunto de atividades que a vítima do dano, normalmente, tinha incorporado ao seu cotidiano e que, em razão do efeito lesivo, precisou modificar em sua forma de realização, ou mesmo suprimir de sua rotina (SOARES, 2009, p.44).

Especialmente, o regime disciplinar imposto de trabalho forçado ou análogo a escravo ajuda a caracterizar o dano existencial ou ao projeto de vida. A jurisprudência trabalhista há muito vem identificando estas situações como dano existencial:

Trabalho análogo ao escravo gera dano existencial. ' O Direito e o Trabalho' por Dorgival Terceiro Neto Júnior

Correio Trabalhista 25.08.2015. Coluna Jurídica.

Foi o que decidiu a Quarta Vara do Trabalho de Marabá-PA, por sentença do Juiz Francisco José Monteiro Junior, condenando uma madeireira a pagar indenização por danos existenciais no valor de R \$ 50 mil, afora danos morais de R \$ 100 mil.

No caso, o empregado exerceu a função de cozinheiro por 17 anos, tendo sido resgatado durante fiscalização móvel do Ministério do Trabalho, em situação análoga a de escravo.

Foram detectadas inúmeras irregularidades e violações dos direitos trabalhistas como jornada de laboral exaustiva, sem direito a repouso semanal remunerado e férias.

O reclamante ingressou com processo na Justiça do Trabalho pleiteando, dentre outros direitos, a reparação por danos extrapatrimoniais e existenciais.

Para o magistrado, "o réu deixou de garantir condições mínimas de conforto e higiene, submetendo assim, os seus trabalhadores a situação extremamente degradante. $\mathrm{Na}$ análise do caso em comento, houve manifestadamente o abuso do direito, o que de acordo com o art. 187 do Código Civil configura ato ilícito".

$\mathrm{E}$, precisamente quanto aos danos existenciais, o magistrado esclareceu que o direito a reparação resta comprovado pois "o reclamante laborava em jornada extremamente exaustiva, comprometendo sua saúde e renunciado de convívio familiar e pessoal, eis que com a jornada que laborava, sem gozar de férias e repouso, tornar-se-ia impossível qualquer convívio social ou êxito em projetos pessoais".

(TRT 8 ${ }^{\mathrm{a}}$. Região - 4 ${ }^{\mathrm{a}}$. VT de Marabá - Proc. 0000718-29.2015.5.08.0129) (TRIBUNAL REGIONAL DO TRABALHO $8^{\mathrm{a}}$ REGIÃO, 2017)

O dano projeto de vida coletivo não é bem desenvolvido nem pela doutrina, nem pela jurisprudência. Contudo, em ações estatais e atividades econômicas o impacto coletivo a comunidades tradicionais ou originárias são facilmente identificáveis, dada a imposição ou transformação no modo de vida das mesmas. Não especificamente sobre estas comunidades, 
mas tratando da possibilidade de reparação de dano coletivo por violação a questões trabalhistas, como aconteceu com o trabalho análogo a escravo, a Justiça do Trabalho mais uma vez saiu à frente:

Uma Ação Civil Pública ajuizada pelo Ministério Público do Trabalho no Maranhão (MPT-MA) resultou na condenação da mineradora Vale em $\mathrm{R}$ \$ 18,9 milhões por dano moral coletivo. A empresa desrespeitou diversas normas de meio ambiente e segurança do trabalho, o que culminou com a morte de cinco funcionários na capital maranhense.

O valor do dano moral coletivo corresponde a $0,05 \%$ do lucro líquido obtido pela Vale em 2011 - R\$ 37,8 bilhões. Além desse montante, a Vale poderá pagar multa diária de $\mathrm{R}$ \$ 200 mil (até o limite de $\mathrm{R}$ \$ 20 milhões), caso não cumpra 31 obrigações de fazer no prazo de 60 dias. A medida visa garantir a integridade física dos trabalhadores da mineradora e das prestadoras de serviços.

"Essa condenação deve servir de caráter pedagógico para que outras empresas não negligenciem o cumprimento das normas. Algumas das irregularidades contribuíram para que ocorressem os acidentes fatais na área da Vale", lembrou a procuradorachefe do MPT-MA, Anya Gadelha Diógenes.

No Maranhão, o MPT investiga a Vale desde 2007. Ao longo desse período, a instituição abriu seis inquéritos civis para apurar denúncias graves de negligência às normas de saúde, meio ambiente e segurança do trabalho.

Um dos piores episódios protagonizados pela Vale ocorreu em abril de 2010, quando sete trabalhadores que prestavam serviço no Píer 3 do terminal portuário da Ponta da Madeira, em São Luís, foram atingidos por uma calha do transportador de minério. Dois deles morreram por esmagamento craniano e asfixia (Hercules Nogueria da Cruz e Ronilson da Silva) e os outros cinco sofreram lesões.

As outras três vítimas fatais foram Clemente Rodrigues Neto, que sofreu uma queda de quase 15 metros de altura; Lusivan Pires Ribeiro e Nilton Freitas Nascimento esses dois pertenciam ao quadro de empresas subcontratadas pela mineradora - e também vieram a óbito na área operacional da Vale.

Além de cumprir as obrigações de fazer, a mineradora deverá garantir que as empresas terceirizadas também acatem a decisão judicial. Entre as medidas a serem adotadas estão: implantação de Programa de Prevenção de Riscos Ambientais e de medidas de prevenção de acidentes e doenças de trabalho; fornecimento de equipamentos de proteção individual adequados; instalação de barreiras físicas resistentes em áreas com risco de queda de pessoas e equipamentos no mar; fornecimento de água potável, filtrada e fresca para os trabalhadores; entre outras determinações.

A sentença foi assinada pelo juiz da $7^{a}$ Vara do Trabalho de São Luís, Francisco Tarcísio Almeida de Araújo.

Da decisão, cabe recurso.

A Ação Civil Pública contra a mineradora Vale é a de $N^{\circ}$ 015360086.2012.5.16.0022 (REPÓRTER BRASIL, 2017).

A questão ambiental é pedagógica para este entendimento tembém, principalmente, tratando do Regime Militar (1964-1985), em que o modelo de desenvolvimento não considerava nem as populações dispostas no território nacional, nem o meio ambiente:

Assim, o dano ambiental existencial não produzirá efeitos deletérios tão somente na rotina dessas comunidades, mas de uma só vez, em vista do caráter multifacetado deste tipo de dano, comprometerá tanto a normalidade de suas vidas quanto a cultura que sustenta suas identidades (GARCIA, 2015, p.87).

Cabe salientar que, falando especificamente em dano projeto de vida, a doutrina latino americana é farta ao tratar o assunto e esta, a partir, principalmente, das formulações de 
Carlos Fernádez Sessarego, vem alimentando os posicionamentos da Corte Interamericana de Direitos Humanos:

\begin{abstract}
"Dano ao projeto de vida" é, como se referiu, o dano mais grave que pode ser cometido contra a pessoa após a perda da vida. Isso porque o "projeto" é o sentido ou razão para cada pessoa ortoga sua vida. É destino ou direção que o ser humano se fixou no curso de sua vida, de acordo com sua vocação (2015, p.225-226). (tradução livre)
\end{abstract}

Mas não só ele, por exemplo, o mexicano Jorge Francisco Calderó Gamboa:

Dano ao projeto de vida está associado com o conceito de realização pessoal, poder conduzir a sua vida e alcançar o destino que se propõe. Em rigor, as opções são a expressão e garantia de liberdade (2005, p.10). (tradução livre)

Como visto, muitas formas pode se dar o dano ao projeto de vida, atingindo esferas diferentes das relações das pessoas, como também em intensidade e amplitudes diversas. Muitos conflitos sociais e socioambientais decorrem de empreendimentos ou atividades que causam este tipo de dano, que alcançam para além de indivíduos, mas projetos de vida de toda uma coletividade. Por isso, merece ser mais estudado.

\title{
2.2. Dano ao projeto de vida na Corte Interamericana de Direitos Humanos
}

O dano ao projeto de vida se constitui numa violação de direitos humanos, não há dúvida disso. Conforme Almeida (2016, p. 27) o projeto existencial é o fio condutor entre o passado, presente e futuro. A Corte Interamericana de Direitos Humanos- CIDH entende que o dano ao projeto de vida está interligado ao direito de liberdade, liberdade de escolha, como também ao direito à vida (AlMEIDA, 2016, p.40). Asssim, pode-se entender que seria um dano que trolhe a liberdade de como se escolhe ter a sua existência.

O direito à vida é entendido de forma mais ampla, como a privação da pessoa de realizar o seu projeto. $\mathrm{O}$ respeito ao modo vida diferenciado, signfica respeito a liberdades fundamentais, a princípios de justiça, como bem descrito por John Rawls:

O interesse fundamental na liberdade e nos meios para fazer um uso equitativo da liberdade é a expressão de verem a si mesmas primariamente como pessoas morais com um direito igual à escolha do próprio modo de vida. Assim, reconhecem os dois princípios de justiça[...] (2008, p.695)

Isto é o que bem entende a CIDH, administrar a sua própria vida para alcançar o seu destino é garantia de liberdade:

O projeto de vida está associado ao conceito de realização pessoal, pois se ampara nas opções que o sujeito pode ter para administrar sua vida e alcançar o seu destino e tais opções representam a expressão garantia da liberdade, tendo em vista que a pessoa pode ser verdadeiramente livre se necessita de opções para conduzir sua existência, levando-a a sua consequente e natural culminação. A eliminação ou prejuízo dessas escolhas resulta e uma redução objetiva da liberdade, sendo que a perda desse valor não pode ser ignorada por este Tribunal (ALMEIDA, 2016, p.39).

A Corte Interamericana traz isto bem claro na sua decisão no Caso Loyaza Tamayo vs. Peru, em que caracteriza o dano ao projeto de vida, quando a pessoa vê a sua existencia alterada por fatores alheios a ela: 
Como tal, é razoável dizer que há violações dos direitos em obstruir gravemente ou impedir a obtenção de resultado esperado, e, portanto, substancialmente alterar o desenvolvimento do indivíduo. Em outras palavras, o "dano ao projeto de vida", entendida como uma expectativa razoável e acessecível no caso específico, envolvendo a perda ou diminuição grave de oportunidades e desenvolvimento pessoal, irreparável ou muito difícil de reparar. Assim, a existência de uma pessoa se vê alterada por fatores além dela, que são impostos de forma injusta e arbitrária em violação das regras em vigor e confiança, que poderiam ser depositadas nos órgãos do poder público forçado a protegê-la e a trazer segurança e a fornecer segurança para o exercício dos seus direitos e satisfação dos seus legítimos interesses (COSTA RICA, 2017, p. 39-40). (tradução própia)

Gamboa (2005, p.26) também dá destaque ao entendimento da CIDH de que dano ao projeto de vida seria uma violação de direitos humanos:

\begin{abstract}
A Corte concebe corretamente projeto de vida como a dimensão mais importante de liberdade ontológica do que consiste o ser humano. É de salientar, que é uma declaração de jurisdição supranacional que contribui significativamente para reorientar e enriquecer o Jurisprudência internacional sobre reparações com a abordagem e a contribuição própria do Direito Internacional dos Direitos Humanos.
\end{abstract}

A reparação para a CIDH deve ser integral, aí incluída a pecuniária. Contudo, esta não deve ser a considerada a mais importante, mas sim medidas que visem restitui o status quo. A condição quista é de atutonomia sobre os rumos, o projeto de sua vida:

A decisão da pessoa resta prejudicada, frustrada, ela torna-se privada do poder de agir, de decidir, escolher o seu destino, seu futuro, o significado da sua existência, sua realização pessoal, sua plenitude, baseado no dom (vocação) da sua vida, objetivando o seu projeto (ALMEIDA; SCHÄFER, 2017, p.4).

Seja numa perspectiva individual ou coletiva, a autonomia por seu própio projeto de vida é um direito e assim deve ser resguardado. Por isso, a importância de se identificar o dano ao projeto de vida, no intituito de se providenciar a coreta reparação.

\title{
3. OS DANOS AO POVO KRENAK PERPETRADOS PELO REGIME MILITAR
}

Os Krenak, como outras etnias indígenas brasileiras, há muito vem sofrendo pelo modelo de desenvolvimento, historicamente, implantado neste território. Eles pertencem à macro etnia jê, que significa essência do ser (SÃO PAULO, 2017), viviam onde hoje são os Estados da Bahia, Espírito Santo e Minas Gerais:

Os Krenak eram outrora um de vários grupos indígenas que habitavam uma vasta região entre os estados de Minas Gerais, Bahia e Espírito Santo e que receberam a denominação genérica de botocudos, devido ao batoque, um pedaço de madeira em forma circular que usavam nos lábios ou nas orelhas. Foi contra os botocudos, guerreiros e temidos.que a Coroa portuguesa decretou no Brasil, por meio de uma série de cartas régias, uma política de guerra, cativeiro e escravização no início do século XIX. Essa determinação levou à criação de sete divisões e e 33 quartéis militares na região do Rio Doce, duas divisões e doze quartéis em Jequiinhoha, duas divisões e quatro quartéis em Mucuri, quatro quartéis em Itanhém ou Jucurucu, quatro quartéis em Prado, quatro quartéis em São Mateus e "outros 26 quartéis espalhados em outros rios de menor porte". Após muita resistência, mortes, epidemias e derrotas, incluindo o sequestro por "civilizados" de crianças indígenas, os índios passaram a viver aldeados perto das unidades militares. No início do 
século XX, o SPI criou alguns postos indígenas, incluindo o Eme, onde ficaram os Krnak. Mais tarde o local foi batizado como posto indígena Guido Marlière, em homenagem a um militar francês enviado para a região em 1819 para continuar a política de atração e "pacificação" dos botocudos (VALENTE, 2017, p.75-76).

O Relatório da Comissão Nacional da Verdade, também aponta que os Krenak, na década anterior a Ditadura Militar, sofreram, mais de uma vez, danos materiais e imateriais, por remoção forçada, em nome do desenvolvimento econômico:

Os Krenak, por exemplo, foram transferidos - com o aval do SPI - de seu território, no município de Resplendor (MG) para a região de Águas Formosas em 1957. A decisão, que respondia à última etapa da ação do órgão para liberar as terras para colonização, foi tomada de forma atropelada e sem nenhum início do planejamento da direção acerca da transferência dos Krenak. Frente às péssimas condições de vida no posto de Águas Formosas, os indígenas retornam à pé, de carro e de trem em uma viagem de três meses e cinco dias (COMISSÃO NACIONAL DA VEDADE, 2017, p.210)

Como sabido, o território original dos Krenak continua a sofrer pelo modelo de desenvolvimento implementado, basta ver aa chamada tragédia de Mariana, na região do Vale do Rio Doce. Mas este artigo irá se deter às violações sofridas no Regime Militar, como se denvolverá a seguir.

\subsection{Os Krenak e o Regime Militar}

As três ações do Estado brasileiro, durante a Ditadura Militar, que causaram diversos danos aos Krenak são a criação da Guarda Rural Indígena (GRIN), a instalação do presídio indígena em suas terras, chamado "Reformatório Krenak"6, e o deslocamento forçado para outro centro de detenção indígena, denominado fazenda Guarani, no município de Carmésia/MG. Os danos sofridos aquela época prejudicaram sua organização, modo de vida, produzindo reflexos até os dias de hoje, como será visto.

O relatório da Comissão Nacional da Verdade (BRASIL, 2017), em referência a questão indígena, aponta o esbulho do território; usurpação do trabalho, confinamento e abusos de poder; remoções forçadas; o tratamento como virtuais inimigos internos; a criação da Guarda Rural Indígena (GRIN); desagregação social; desassitência por parte do poder público; prisões torturas e maus-tratos; o reformatório Krenak; como algumas das violações perpetradas pelo Regime Militar. Percebe-se que algumas destas ações, como a criação da GRIN e do reformatório Krenak, têm ligação direta com a população aqui em comento, e outras são comuns a diversos outros povos durante o período citado. Dentre as recomendações do relatório está a:

Criação de grupo de trabalho no âmbito do Ministério da Justiça para organizar a instrução de processos de anistia e reparação aos indígenas atingidos por atos de

\footnotetext{
${ }^{6}$ O Reformatório Krenak foi instituído com fundamento no Decreto 5484/1928:

“Art. 28. São equiparados aos menores de que trata o art. 30 do Codigo Penal os indios nomades, os arranchados ou aldeiados e os que tenham menos de cinco annos de estabelecidamente em povoação indigena.

$\S 1^{\circ} \mathrm{O}$ indio de qualquer das tres categorias acima, que tiver praticado qualquer infracção, cobrando com discernimento, será recolhido, mediante requisição do inspector competente, a colonias correccionaes, ou estabelecimentos industriaes disciplinares, pelo tempo que ao mesmo inspector parecer, comtanto que não exceda de cinco annos."
} 
exceção, com especial atenção para os casos do Reformatório Krenak e da Guarda Rural Indígena, bem como aos demais casos citados neste relatório (BRASIL, 2017).

Este documento oficial do Estado brasileiro faz prova das violações sofridas e indica mecanismos de reparação. Isto necessita ser acompanhado, para não se perder com mudanças e interrupções de governos. Estritamente sobre o reformatório, fala de tortura, trabalhos forçados e desaparecimento de presos:

O Estado brasileiro criou, no final dos anos 1960, uma cadeia oficial em território Krenak, exclusiva para a detenção de indígenas, sobre a qual colhemos denúncias de casos de morte por tortura no tronco, trabalho forçado e desaparecimento de prisioneiros. É recomendável a continuidade da investigação - tanto sobre as cadeias para índios, como sobre a Guarda Rural Indígena -, que não se esgota com esse trabalho (BRASIL, 2017, p. 240-241).

A criação da GRIN deu-se por ato da Fundação Nacional do Índio- FUNAI. A partir daí teve-se abertura para o "Reformatório" Krenak, em Resplendor (MG). Continuando a política de "pacificação", para atender interesses econômicos outros, essas medidas se deram em resposta a rebelião dos Maxacali de Minas Gerais, em 1966 (VALENTE, 2017, p.73). O Capitão da Polícia Militar Manuel dos Santos Pinheiro, que havia sido enviado pela FUNAI para conter a supramencionada rebelião, tornou-se o chefe da GRIN. De início pretendia reunir mais de três mil indígenas para defender os aldeamentos e disciplinar internamente os mesmos. Receberam treinamento no Batalhão Escola da Polícia Militar de Belo Horizonte, tendo a primeira turma cinquenta e sete alunos, dentre kraô, xerente e maxacali, que iniciaram a formação em novembro de 1969. Como foi dito no Jornal O Globo de 18 de novembro de 1969, o treinamento visava formar um "soldado branco".

A expressão utilizada, formar um "soldado branco", já demonstra a intenção de descaracterizá-los, atingindo sua cultura e forma de organização. O documentário de Jesco von Puttkamer (CAPRIGLIONE, 2017), doado em 1977 ao IGPA (Instituto Goiano de PréHistória e Antropologia), da Pontifícia Universidade Católica de Goiás, expõe a violência a cultura destes povos, na cerimônia de formatura que ocorreu em Belo Horizonte, em fevereiro de 1970. Ao todo foram oitenta e quatro indígenas formados na GRIN e, além das etnias acima descritas, também membros do povo carajá e gaviões. O documentário mostra, inclusive, que ensinaram famigeradas técnicas de tortura da Ditadura Militar, como o "paude-arara", encenado pelos indígenas em seu desfile de formatura. Supõe-se que o filme não foi destruído pelo Regime, pois sua identificação foi de "Arara", ao que remeteram a outra etnia, que fica na região norte do país.

Válido também salientar que a Comissão Parlamentar de Inquéritos-CPI sobre o Serviço de Proteção aos Índios-SPI terminou por extinguir o órgão e criar a FUNAI, trouxe diversas denúncias dos governos militares por genocídio a populações indígenas:

O início do século XX verá um movimento de opinião dos mais importantes, que culminará na criação do Serviço de Proteção aos Índios (SPI), em 1910 (Souza Lima in Carneiro da Cunha [org.] 1992). O SPI extingue-se melancolicamente em 1966 em meio a acusações de corrupção e é substituído pela Fundação Nacional do Índio (funai): a política indigenista continua atrelada ao Estado e as suas prioridades. Os anos 1970 são os do "milagre", dos investimentos em infraestrutura e em prospecção mineral- é a época da Transamazônica, barragem de Tucuruí e da de Balbina, do Projeto Carajás. Tudo cedia ante a hegemonia do "progresso", diante do qual os índios eram empecilhos[...] (CUNHA, 2012, p.21) 
A GRIN foi uma resposta do Regime, no intuito de dizer que os próprios indígenas estavam se protegendo. Mas não demorou muito a aparecer denúncias de violência e arbitrariedades por parte da GRIN. Além disto, a mesma teve reflexo na organização e na cultura das comunidades indígenas, como já dito:

Na terra dos Kraô, a experiência também foi um desastre. Por volta de 1967, os índios somavam cerca de seiscentos indivíduos. Desse total, 28 foram transformados em grins. A partir daí, a produção de alimentos foi reduzida na área, pois os guardas, suas mulheres e familiares deixaram de se dedicar a atividades agrícolas, passando a viver dos salários da Grin. Para alimentar a guarda, a Funai n instalou uma cantina na área indígenas, onde os índios podiam comprar produtos industrializados. Isso também provocou a redução da produção agrícola e as atividades de caça. Outro problema foi que a Grin passou a controlar a saída dos índios para os núcleos urbanos, tolhendo a liberdade de todos na área (VALENTE, 1974, p.74).

Quanto aos Krenak, o reformatório criado e a GRIN provocaram um desastre. A população virou, de fato, prisioneira em seu próprio território, sob a égide de uma disciplina imposta:

Os krenak se tornaram, em amarga ironia. Prisioneiros em suas próprias terras. Para entrar ou sair do local, precisavam de autorização da Grin. A mesma regra valia para a travessia do rio, de canoa. Certo dia, José Alfredo desrespeito a norme e, por isso, ficou dezessete dias preso. De dia ser solto para trabalhar na roça, sob a vigilância de guardas armados, mas à noite era trncafiado. Ele presenciou espancamentos e pelo menos uma tortura por afogamento (VALENTE, 2017, p.77).

A CNV apurou o regime de exceção ao qual eram sujeitos os indígenas confinados no chamado reformatório Krenak:

Bater era normal para eles. Se o índio tentava se justificar por alguma acusação, batiam com cassetete grande, depois jogavam na prisão. Não podiam nem perguntar por que estavam sendo punidos. Também batiam de chicote. Algemavam o preso dentro da cadeia e ele não podia falar, argumentar. Ameaçavam com arma. Os mais antigos contam que quando matavam um índio, jogavam no rio Doce e diziam pros parentes que tinha ido viajar.

Quando estavam muito debilitados, jogavam no hospital. A gente não sabia se estavam mesmo no hospital ou se foram massacrados ou morreram de fome, sede. A gente não via morrer aqui, era quando estavam no hospital. Até a década de 1980 nosso povo sofreu bastante com os militares (BRASIL, 2017, p.245).

Como apontado acima, para além do Reformatório Krenak e da criação da GRIN, a população em questão também sofreu deslocamento forçado, para atender a interesses de fazendeiros da região na terra indígena:

Em 1972, os krenak foram forçados pela Funai ao seu terceiro deslocamento. Agora iriam para um local conhecido como Fazenda Guarani, no município de Carmésia, a cerca de 350 quilômetros por rodovia. Tratava-se de uma propriedade da Polícia Militar de Minas. O comando da Funai decidiu pela transferência para liberar a área dos krenak aos fazendeiros da região. Alegou que estava fazendo uma troca de terras. Em vez de retirar os fazendeiros, retirou os índios. José Alfredo viu quando seu amigo Joaquim Grande, ao se recusar fazer a mudança, foi algemado e jogado num carro (VALENTE, 2017, p.77). 
Isto causou uma desestrururação do povo Krenak, seu modo de vida, que os levou a quase extinção:

Em Guarani, os Krenak descobriram que o local era habitado por vários policiais e indíos de outras etnias. Parte deles não quis ficar e decidiu rumar para outras cidades da região. Só sete nos depois os krenak voltarial em definitivo para a terra em Resplendor, também a contragosto da Funai(VALENTE, 2017, p.77).

O desterro também foi reconhecido no Relatório da Comissão Nacional da Verdade:

Apesar dos últimos registros de movimentação de presos transferidos para Icatu serem de agosto de 1967, no jornal Luta Indígena, no 6, de agosto de 1978, é registrada a presença de índios Kaingang, originários daquela terra, convivendo com indígenas Terena, Guarani, Krenak, Fulni-ô e Pankararu, que vieram "transferidos" na década anterior, quando a cadeia funcionava em Icatu, e permaneceram desterrados de suas raízes, no interior de São Paulo (BRASIL, 2017, p. 243).

O Relatório da CNV, concluiu, então, que a experiência causou diversos danos às populações indígenas envolvidas, dentre elas, claro, a Krenak:

A CNV, mesmo que ainda não tenha as respostas para as questões acima,
com base na documentação reunida reconhece, no Reformatório Krenak e na
Fazenda Guarani (que o sucedeu), a sua abrangência nacional quanto à função de
prisão de índios rebeldes, encarcerando indígenas de 23 etnias. Ademais,
especificamente para a população Krenak, obrigada a viver sob as mesmas
condições de índios presos em suas terras, o reformatório assume um caráter de
"campo de concentração", conforme denunciado no Tribunal Russell II, ou "prisão
domiciliar", como descrito no caso Aikewara. Os indícios levantados relacionam
esse reformatório aos centros de torturas e, portanto, as investigações deverão ser
aprofundadas pelo Estado brasileiro (BRASIL, 2017, p.245).

No caso dos Krenak, fica bem claro o dano ao complexo de relações que os identifica como um povo. Suas atividades cotidianas como a caça e a pesca, o seu direito de ir e vir e seus saberes e fazeres que constituem a sua cultura foram fortemente prejudicados com a criação da GRIN, do Reformatório Krenak e com a remoção forçada para a Fazenda Guarani. A doutrina ressalta que o dano existencial, tal qual como o dano ao projeto de vida, não se dá com simples alterações de cotidiano, mas mudanças drásticas e intensas, bem caracterizadas nas mudanças impostas pelos Governos Militares e esta população indígena:

[...] deve-se mencionar que se trata de uma mudança muito grande na vida das pessoas, como noites em claro, sacrifícios, renúncias, pensionamento, fins de semana perdidos, diminuição do horizonte, entre outros tipos de consequência. (LUTZKY, 2012, p.141)

A política indigenista do Regime Militar deu continuidade e intensificou diversas violações do Estado brasileiro ao povo krenak. Especificamente, as três ações em destaque da Ditadura contribuiram para a desorganização desta população, seu modo de vida, suas expectativas e aspirações. Forçados a deslocamentos e a uma disciplina de sistema prisional, os krenak, dentre outros danos sofridos, também foram atingidos em seu projeto de vida, por este não coincidir com os interesses do Governo Federal da época. 


\subsection{A Ação Civil Pública do Ministério Público Federal de reparação aos danos causados aos Krenak}

A ação do $\mathrm{MPF}^{7}$ pede que o Estado brasileiro seja responsabilizado por graves violações de direitos humanos sofridas pelos krenak, durante a Ditadura Miliar. Trata-se da Ação Civil Pública n ${ }^{\circ}$ 64483-95.2015.4.01.3800, protocolada no dia 16 de dezembro de 2015, que tem como reús a União, o Estado de Minas Gerais, a Fundação Nacional do Índio (Funai), a Fundação Rural Mineira (Ruralminas) e o oficial militar reformado da Polícia Militar de Minas Gerais, Manoel dos Santos Pinheiro, chefe da GRIN, já citado acima. O MPF aponta, como anteriormente descrito, um ambiente de exceção, trabalhos forçados, tortura, remoção compulsória e intensa desagragação social. Esta última, decorrente das demais violações é que indica que também houve dano ao projeto de vida desta população. O MPF comprova também danos psicológicos, por meio do parecer do psicólogo Bruno Simões Gonçalves, especialista em populações tradicionais. O documento traz que a violência perpetrada pela Ditadura causou intenso sofrimento individual e traumatização psicossocial coletiva da etnia.

No dia 06 de dezembro de 2016, esta ação do MPF já obeteve a sua primeira vitória, tendo sido concedida tutela antecipada obrigando a Fundação Nacional do Índio (FUNAI) a concluir, no prazo de um ano, o processo de Identificação e Delimitação da Terra Indígena Krenak de Sete Salões, adjacente ao atual território da etnia localizado na região leste do estado de Minas Gerais, e ainda outras medidas:

Por todo o expendido, defiro parcialmente a tutela de urgência pleiteada para:

1. Determinar à FUNAI que ultime a conclusão do processo administrativo FUNAI n ${ }^{\circ}$ 08620-008622/2012-32, de Identificação de Delimitação da Terra Indígena Krenak de Sete Salões/MG, no prazo de 01 ano, como requerido no item 2 . 1 da inicial, quando, então, após definida a extensão do território indígena, será possível estabelecer ações de reparação ambiental no tocante às terras ocupadas pelos Krenak, a ser promovida tanto pela União quanto pelo Estado de Minas Gerais, sem prejuízo da participação da FUNAI e da comunidade Krenak em medidas reparatórias que constem do acordo da União com as empresas Vale e Samarco e que possam atingir os limites territoriais do povo Krenak;

2. Determinar à União e à FUNAI que, no prazo de 180 dias, criem um grupo de trabalho que deverá elaborar a tradução, para a língua Krenak, da versão atualizada da Constituição da República de 1988, da Convenção n ${ }^{\circ} 169$ da Organização Internacional do Trabalho e do relatório final da Comissão Nacional da Verdade sobre as violações de direitos humanos dos povos indígenas, entregando os textos traduzidos ao povo Krenak tão logo sejam concluídos os trabalhos.

3. Determinar à FUNAI, à União, ao Estado de Minas Gerais à RURALMINAS que, no prazo de 180 dias, entreguem ao povo da comunidade Krenak de Resplendor/MC cópia de todos os documentos governamentais, mantidos sob qualquer meio impresso, digital ou audiovisual, produzidos no período da ditadura militar, especialmente os pertinentes ao Reformatório Krenak e à transferência compulsória desse povo à Fazenda Guarani;

4. Determinar à FUNAI e ao Estado de Minas Gerais, mediante entendimento com a Secretaria Estadual de Educação, a extensão, mediante consulta ao povo Krenak de Minas Gerais, das oficinas de trabalho linguístico mencionadas às f Is. 1041/1042, como forma de resgatar e preservar sua cultura, estabelecendo prazo de 180 dias para início dos trabalhos;

5. Determinar à União que diligencie junto ao Arquivo Nacional para que este reúna, sistematize e publique, na rede mundial de computadores, no prazo de 01 ano, toda a documentação relativa às graves violações dos direitos humanos dos povos

\footnotetext{
${ }^{7}$ A ação é de autoria dos Procuradores Edmundo Antonio Netto Dia Junior, Maria Rezende Capucci, Marlon Alberto Weichert, Antonio do Passo Cabral, Felipe Valente Siman e Júlio José Araújo Júnior
} 
indígenas durante o período de 1967 a 1988, especialmente aqueles relacionados com a instalação do Reformatório Krenak, a transferência forçada de povos indígenas para a Fazenda Guarani e o funcionamento da Guarda Rural Indígena em Minas Gerais (JUSTIÇA FEDERAL, 2017);

O Sra. Manoel Pinheiro chegou a entrar com embargos de declaração, por não se ter apreciado a sua arguição de ilegitimidade passiva. O juízo acolheu, acrescendo à decisão anterior, sua apreciação sobre esta preliminar a rejeitando.

A ação da MPF parte dos três fatos já expostos, que ocorreram durante a Ditadura Militar, a criação da GRIN, a instalação do Reformatório Krenak e a remoção dos mesmos para a Fazenda Guarani, no Município de Carmésia-MG. Em vários momentos a petição incial do MPF traz relatos e provas que permitem a discussão se houve também dano ao projeto de vida. Destaca-se, por exemplo, a proibição da utilização da língua: "Ninguém podia falar a língua indígena; só podia falar a língua 'do branco'; se falasse língua indígena, apanhava e ficava preso"(MINISTÉRIO PÚBLICO FEDERAL, 2017, p. 17). Reú na ação, a época Capitão Pinheiro, falava em reeducação, que poderia ser também chamado de política assimilação ou de retirada das culturas indígenas. Esta conduta foi bem expressa pelo réu em entrevista Jornal do Brasil, em 1972 (27 de agosto):

Sim, o índio é fator de segurança nacional, pois quando ele se revolta, cria a desordem, a subversão, e deste modo, depois de preso pela GRIN e enviado a Crenaque, para reeducar-se e ser um índio bom (Jornal do Brasil, 27/08/1972 - Anexo 6) ( MINISTÉRIO PÚBLICO FEDERAL, 2017, p.19)

A proibição de utilizar os seus nomes indígenas é outro ato de descaracterização de sua cultura, de seu modo de ser:

Os militares proibiam os nomes indígenas como forma de repressão; todos os indígenas passaram a ser obrigados a dar nome em português para os filhos. Como forma de se proteger e tentar criar um "laço de amizade" com os militares, alguns indígenas chegaram a ser batizados com os nomes dos militares, como, por exemplo, o indígena que foi chamado de Oredes, nome de um temido militar. (MINISTÉRIO PÚBLICO FEDERAL, 2017, p. 34)

Dejanira Krenak relata ao MPF que ainda se aterroriza ao ver a polícia militar, destacando a violência sofrida, inclusive, pela proibição de realizar seus cultos sagrados, de danças, fogueiras, de conversar com os encantados, ou fazer rituais de reza. Esta realidade levou à Procuradoria da República concluir:

Verifica-se, portanto, que a intervenção militar foi marcada pela destruição sistemática de modos de vida e pela desagregação social e cultural do Povo Krenak, o que caracteriza a prática de etnocídio (MINISTÉRIO PÚBLICO FEDERAL, 2017, p. 34).

Um dos impactos na cultura é o ritual de passagem, quando o indígena morre. Devido ao reformatório e a remoção, os mortos e desparecidos não poderam passar por este rito. E os seus descedentes não vão também poder, porque só poderiam se os seus atepassados tivessem também passado. Esta intervenção na ligação dos Krenak com seu passado, poderá ter atingido a realização fenomênica do seu projeto devida: "Em outras palavras, decide no presente, baseado no passado, para realizar o futuro, esse é o projeto de vida, sua 'realização fenomênica' (ALMEIDA, 2016, p. 32)”. 
A ação também denuncia que a remoção forçada ocorrida para a Fazenda Guarani privou os Krenak de viverem da caça e da pesca, como era seu costume, para além dos roçados. A área nem um rio possuía, como em seu território original. O clima era mais frio e os indígenas sofreram assim com a mudança. Há o relato da morte de um senhor de idade, conhecido como Índio Jacó , que teria morrido "apaixonado", saudoso de tristeza, esperando voltar a sua terra. Ainda cabe ressaltar que a remoção em comento foi feita em vagão de carga e não de passageiros, tratando os indígenas como animais, conforme trazido pela petição inicial em questão.

Os danos causados, como demonstrado, atingiram indivíduos, mas não tão somente, foram coletivos, como exposto:

No que se refere à dimensão coletiva do impacto da violência estatal sobre o modo de vida dos Krenak, o relatório destaca dois processos brutais resultantes dos atos de violência perpetrados pelos Requeridos contra os indígenas: a humilhação social e a desagregação cultural(MINISTÉRIO PÚBLICO FEDERAL, 2017, p. 65).

Apesar da ação do MPF apenas pedir e utilizar o termo "danos morais coletivos", outros pedidos feitos na mesma ação parecem ir ao encontro de reparar o dano ao projeto de vida, quais sejam: a recuperação ambiental de suas terras, esbulhadas e degradadas durante o período da ditadura militar; entregar aos Krenak todos os documentos governamentais, mantidos sob qualquer meio impresso, digital ou audiovisual, produzidos no período da ditadura militar, referentes à etnia, ao Reformatório Krenak e à transferência compulsória desse povo à Fazenda Guarani; implementar ações para registro, transmissão e ensino da língua Krenak; implementar ações e apoiar iniciativas indígenas destinadas a resgatar e preservar a cultura do povo Krenak; concluir o processo administrativo Funai $n^{\circ}$ 08620-008622/2012-32,de Identificação de Delimitação da Terra Indígena Krenak de Sete Salões/MG. Contudo, coloca-se aqui se não caberia, de forma a procurar mitigar o dano sofrido, pedir indenização por danos ao projeto de vida do povo Krenak. Mas isto é feito, sem estar posto de forma expressa a denominação do dano. A linha seguida pelo MPF coaduna com o diferencial devido às peculiaridades que existem entre dano material e imaterial, condizentes os pedidos feitos com uma reparação mais eficaz:

\footnotetext{
A diferença entre as lesões reside, substancialmente, na formar em que se opera a sua reparação. Enquanto no caso dos danos materiais a reparação tem como finalidade repor bens lesionados ao seu status quo ante, ou possibilitar à vítima a aquisição de outro bem semelhante ao destruído, o mesmo não ocorre, no entanto com os danos extrapatrimoniais. Neste é impossível repor as coisas ao estado original. A reparação, em tais casos, reside no pagamento de uma soma pecuniária, fixada em face do arbitrium boni iuris do magistrado, de forma a possibilitar à vítima uma compensação em decorrência da dor íntima vivenciada (REIS, 2010, p. 7).
}

O dano existencial ou dano ao projeto de vida decorre das consequências trazidas pelo ato em si, tendo em vista que, normalmente, o dano moral já é sentido concomitante, sem prejuízo de se estender posteriormente no tempo, como o dano pissicossocial sofrido pelos Krenak:

[...] ]outrossim, o dano moral normalmente ocorre junto com o evento lesivo; o dano existencial, em momento posterior, pois é decorrente de um sequência de atos (Lutzky, 2012, p. 142). 
Levanta-se, então, o questionamento se houve dano ao projeto de vida á população Krenak, tendo em vista os fatos trazidos pela Comissão Nacional da Verdade e pela Ação Civil Pública do Ministério Público Federal. Seria dano decorrente de uma sequência de atos sofridos durante o Regime Militar. Analisar o encademento dos fatos e suas consequencias poderá ajudar a encontrar a resposta.

\section{CONCLUSÃO}

Os indígenas Krenak há muito vem sofrendo violações por parte do Estado Brasileiro, inclusive antes, quando ainda colônia portuguesa. Instituiu-se todo um sistema de repressão de divisões militares e quartéis, numa política "guerra justa", que foi intensificada no sec. XIX. Mesmo assim, no início de do sec. XX ainda havia cerca de 5 mil Krenak, mas já em 1920 só havia 600 (MINISTÉRIO PÚBLICO FEDERAL, 2017, p. 14), e os atos do Regime Militar, os levaram a quase a extinção.

O artigo, então, analisou as ações estatais da Ditadura Militar que causaram diversos danos ao povo Krenak, como também a outras etnias, quais sejam, a criação da Guarda Rural Indígena (GRIN), a instalação do presídio indígena em suas terras chamado "Reformatório Krenak" e o deslocamento forçado para outro centro de detenção indígena, chamado de Fazenda Guarani.

Estes três episódios estão bem relatados no Relatório da Comissão Nacional da Verdade, Volume II (Textos temáticos), como na Ação Civil Pública $\mathrm{n}^{\circ}$ 6448395.2015.4.01.3800 (14 ${ }^{\mathrm{a}}$ Vara da Justiça Federal em Minas Gerais), impetrada pelo Ministério Público Federal, em 16 de dezembro de 2015. Esta Ação já obteve antecipação de tutela, em 06 de dezembro de 2016, a diversos pedidos, inclusive, alguns que poderão reparar possível dano ao projeto de vida, pois têm o intutito de reconstituir a língua, a cultura, bem como garantir o território do povo Krenak.

Os dois documentos referidos neste artigo demonstram que o povo Krenak foi submetidos à humilhação e à desagregação social. Muitos foram os atos violadores, como privação de liberdade, trabalho forçado, violência sexual, tortura, remoção forçada, etc. Se não bastasse, ainda foram impedidos de utilizarem seus nomes originais, de falarem sua língua e de realizarem seus cultos, danças e rituais.

Como dito, o Ministério Público Federal fez inúmeros pedidos que visam esta reparação, o que também estaria em conformidade a Corte Interamericana que, nesses casos, entende que o mais importante é procurar restituir ou se aproximar ao máximo a condição existente afetada pelo dano. Todavia, o MPF também pede indenização por danos morais coletivos, fudamentada em parecer pissicossocial, e aqui este artigo discute se também não deveria haver indenização por dano ao projeto de vida coletivo.

O povo krenak, como tantos outros povos indígenas no Brasil, sofreu e sofre danos dos mais variados, em virtude do modelo econômico adotado no país, em que sua existência termina sendo considerada "empecilho". Os territórios das populações indígenas são desejados pela especulação de terras e empreendimentos econômicos diversos, que não levam em conta as comunidades que lá vivem, instrumentalizando, muitas vezes, o poder estatal para perpetrar violações de direitos humanos. É certo que o povo Krenak foi obstacularizado em sua liberdade de escolher seus próprios rumos pelos atos da Ditadura Militar:

O projeto de vida é a liberdade, que desponta de uma decisão, uma escolha de um projeto de um projeto específico, avaliando/estimando diante das oportunidades apresentadas, de acordo com seus valores (o que se mostra valioso para realizar), experiências e vocações pessoais, em um determinado período histórico visando o 
futuro, dano um sentido à nossa existência e é desta maneira que a vida humana se comporta (ALMEIDA, 2016, p. 28).

A identificação do dano ao projeto de vida poderá ser mais um instrumento a ser utilizado para a reparação ou mesmo defesa destas comunidades diante do desrespeito e descaso em relação aos seus territórios e culturas.

\section{REFERÊNCIAS}

ALMEIDA, Greicy Fraga. O dano ao projeto de vida da Corte Interamericana de Direitos Humanos: o caso Cabrera vs. México e o ingresso no Direito Brasileiro. Dissertação. Porto Alegre: UniRitter, 2016.

ALMEIDA, Greicy Fraga; SCHÄFER, Gilberto. Dano existencial ou dano ao projeto de vida?

Disponível

em:

https://www.uniritter.edu.br/files/sepesq/arquivos_trabalhos/3612/662/752.pdf. Acesso em: 12 de maio 2017.

BRASIL. Comissão Nacional da Verdade. Relatório. Volume II. Disponível em: http://www.cnv.gov.br/images/pdf/relatorio/volume_2_digital.pdf. Acesso em: 11 de maio 2017.

CAPRIGLIONE, Laura. Vídeo mostra indígenas desfilando com gente no pau-de-arara e sugere que ditadura ensinou indígenas a torturar. Disponível em: http://acervo.racismoambiental.net.br/2012/11/12/video-sugere-que-ditadura-ensinouindigenas-a-torturar/. Acesso em: 12 de maio 2017.

COSTA RICA. Corte Interemaricana de Drechos Humanos. Caso Loayaza Tamayo Vs. Peru. SETENCIA DE 27 DE NOVIEMBRE DE 1998. http://www.corteidh.or.cr/docs/articulos/seriec_42_esp.pdf\%3E. Acesso em : 14 de maio 2017.

CUNHA, Manuela Carneiro da. Índios no Brasil:história, direito e cidadania. 1 ed. São Paulo: Claro Enigma, 2012.

GAMBOA, Jorge Francisco Calderón. Reapación del daño al proyecto de vida por violaciones a derechos humanos. México: Porrúa, 2005.

GARCIA, Fernando Murilo Costa. Dano Ambiental Existencial: reflexo do dano aos pescadores artesanais. Curitiba: Juruá, 2015.

JUSTIÇA FEDERAL. Ação Civil Pública n 0064483-95.2015.4.01.3800 Diposnível em: http://processual.trf1.jus.br/consultaProcessual/processo.php?proc $=644839520154013800 \&$ se

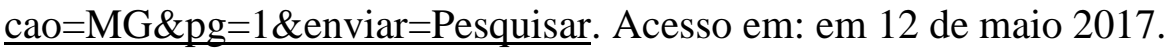

LUTZKY, Daniela Courtes. A reparação de danos imateriais como direito fundamental. Porto Alegre: Livraria do Advogado, 2012.

MINISTÉRIO PÚBLICO FEDERAL. Ação Civil Pública Reformatório Krenak. Disponível em: file:///G:/Downloads/ACP\%20Reformatorio\%20Krenak.pdf. Acesso em: 12 de maio.

RAWLS, Jonh. Uma teoria de justiça. $3^{\text {a }}$ ed. São Paulo: Martins Fontes, 2008, p. 695.

REIS, Clayton. Dano Moral. $5^{\text {a }}$ ed. Rio de Janeiro: Forense, 2010, p.7.

REPÓRTER BRASIL. Vale é condenada em R\$ 18,9 milhões pela Justiça do Trabalho. Disponível em: http://reporterbrasil.org.br/2013/11/vale-e-condenada-em-r-189-milhoes-pelajustica-do-trabalho/. Acesso em: 14 de maio 2017.

SÃO PAULO. Os krenak. Disponível em: https://www.museuindiavanuire.org.br/indiavanuire/os-krenak. Acesso em: 11 de maio 2017.

SESSAREGO, Carlos Fernández. Derecho y persona. 5 ed. Ciudad Autónoma de Buenos Aires: Astrea, 2015. 
Deslinde Conceptual entre "Daño a la Persona", "Daño al Proyecto de

Vida" y "Dano Moral”. Portal de Información y Opinión Legal - Revista Foro Jurídico Faculdade de Derecho da Pontifícia Universidad Católica del Perú, Lima, Año 1, nº. 2, jul 2003. Disponível em: <http://dike.pucp.edu.pe/bibliotecadeautor_carlos_fernandez_cesareo/articulos/ba_fs_6.PDF >. Acesso em: 14 de maio 2017.

SOARES, Flaviana Rampazzo. Responsabilidade civil por dano existencial. Porto Alegre: Livraria do Advogado, 2009.

STOCO, Rui. Tratado de responsabilidade civil: doutrina e jurisprudência. $7^{\mathrm{a}}$ ed., atualizada e ampliada. São Paulo: revista dos Tribunais, 2007.

TRIBUNAL REGIONAL DO TRABALHO $8^{\mathrm{a}}$ REGIÃO. Trabalho análogo ao escravo gera dano existencial. Disponível em: http://www.trt13.jus.br/informese/noticias/2015/08/trabalho-analogo-ao-escravo-gera-dano-existencial-o-direito-e-0-

trabalho-por-dorgival-terceiro-neto-junior TRINDADE, Antonio A. Cançado; BURELLI, Arílio Abreu. Voto razonado conjunto de los jueces. Disponível em: https://archivos.juridicas.unam.mx/www/bjv/libros/5/2066/4.pdf. Acesso em: 18 de maio 2017.

VALENTE, Rubens. Os fuzis e as flechas: história de sangue e resistência indígena na ditadura. 1 ed. São Paulo: Companhia das Letras, 2017. 